\title{
Políticas sociales y nuevos gobiernos en Argentina y Brasil: un balance a partir de los programas Asignación Universal por Hijo y Bolsa Família
}

\author{
María Virginia Quiroga \\ Consejo Nacional de Investigaciones Científicas y Técnicas - Universidad Nacional de Río Cuarto, Córdoba, Argentina \\ Email: mvirginiaq@yahoo.com.ar \\ Lucía Constanza Juncos Castillo \\ Universidad Nacional de Río Cuarto, Córdoba, Argentina \\ Email: castilloluciac@gmail.com
}

\begin{abstract}
Resumen: Los gobiernos de Mauricio Macri en Argentina y de Michel Temer en Brasil destacaron en el escenario suramericano por la pretensión de compatibilizar medidas económicas de corte neoliberal (típicas de los años noventa) con la continuidad de políticas sociales reforzadas durante la ola progresista (primera década del siglo XXI). En esa línea, ambos presidentes apelaron a discursos en los que afirmaban la preocupación por la cuestión social y prometían la reducción de la pobreza; para ello otorgaron continuidad a los principales programas sociales implementados en la década previa: la Asignación Universal por Hijo y la Bolsa Familia. Haciendo foco en el análisis de los programas sociales mencionados, se argumenta que no sólo han sufrido recortes presupuestarios; sino que se han alejado de un enfoque de derechos, aplicándose en contextos de ajuste y recesión. En consecuencia, pasarían a considerarse como políticas para contener la conflictividad social, antes que como instrumentos para mejorar la calidad de vida de sus beneficiarios.
\end{abstract}

Palabras clave: Programas sociales, conflictividad social, giro a la derecha, neoliberalismo.

\section{Social policies and new governments in Argentina and Brazil: an assessment of the Universal Child Allowance (Asignación Universal por Hijo) and Family Grant (Bolsa Familia) programs}

\begin{abstract}
The governments of Mauricio Macri in Argentina and Michel Temer in Brazil stood out on the South American scene for their attempt to make neoliberal economic measures (typical of the 1990s) compatible with the continuity of social policies reinforced during the progressive wave (first decade of the 21st century). Following this line, both presidents appealed to speeches in which they affirmed their concern for the social issue and promised to reduce poverty; to this end, they granted continuity to the main social programs implemented in the previous decade: the Universal Child Allowance (Asignación Universal por Hijo) and the Family Grant (Bolsa Familia). Focusing on the analysis of the above-mentioned social programs, it is argued that they have not only suffered budget cuts, but have also moved away from a rights-based approach, being applied in contexts of adjustment and recession. As a result, they would be considered as policies to contain social conflict, rather than instruments to improve the quality of life of their beneficiaries.
\end{abstract}

Key words: social programs; social conflict; right-wing shift; neoliberalism.

\section{Políticas sociais e novos governos na Argentina e no Brasil: Um olhar a partir dos programas Asignación Universal por Hijo e Bolsa Família}

Resumo: Os governos de Mauricio Macri na Argentina e de Michel Temer no Brasil se destacaram no cenário sul- 
americano por causa da reivindicação das possibilidades de conciliar medidas econômicas neoliberais (típicas da década de 1990) com a continuidade de políticas sociais fortalecidas durante a onda progressista (primeira década do século XXI). Neste sentido, os dois presidentes apelaram a discursos que afirmavam sua preocupação com a questão social e as promessas para reduzir a pobreza; para esse fim, deram continuidade aos principais programas sociais da década anterior: Asignación Universal por Hijo e Bolsa Família.

Centrando-se na análise dos programas sociais acima mencionados, argumenta-se que eles não só sofreram cortes orçamentais; mas também ficaram afastados de uma abordagem de direitos, e imersos em contextos de ajuste e recessão. Consequentemente, esses programas seriam considerados como políticas para conter conflitos sociais, em vez de instrumentos para melhorar a qualidade de vida de seus beneficiários.

Palavras chave: políticas sociais; conflitos sociais; giro à direita; neoliberalismo.

\section{Introducción}

Desde el 2015 en adelante, la expansión territorial de los proyectos progresistas en América Latina parece haberse reducido y estancado; por el contrario, se evidenciaría un creciente «giro a la derecha» (Ansaldi, 2017; López Segrera, 2016 a y b). En ese sentido, el nuevo mapa político regional abarcaría las presidencias de Horacio Cartes (2013-2018) y Mario Abdo Benítez (2018-2022) en Paraguay; Enrique Peña Nieto en México (2014-2018)'; Juan Carlos Varela en Panamá (2014-2019); Mauricio Macri en Argentina (2015-2019); Michel Temer (2016-2018) y Jair Bolsonaro (2018-2022) en Brasil; Sebastián Piñera en Chile (2018-2022), e Iván Duque en Colombia (20182022). Muchos de ellos presentan una biografía que destaca más por su cercanía al mundo de los negocios que al de la política, conforman gabinetes con representantes de los sectores empresariales y privilegian las medidas de corte regresivo, cuyo impacto redundaría en la profundización de los patrones de desigualdad.

El presente texto propone un análisis, aún incipiente y exploratorio, de un rasgo particularmente distintivo de los gobiernos de Mauricio Macri (Argentina) y de Michel Temer (Brasil): la pretensión de compatibilizar medidas económicas de corte neoliberal (típicas de los años 90) con la continuidad de políticas sociales reforzadas durante la ola progresista (en la primera década del siglo XXI). De allí que nos planteamos un interrogante central: ¿cuáles son las características y tensiones que reviste esa vinculación en los contextos recientes de Argentina y Brasil? Para ello nos detenemos en el análisis de los dos programas sociales de mayor trascendencia y alcance: Asignación Universal por Hijo (AUH) y Bolsa Família (BF), tratando de dilucidar los cambios y reconfiguraciones operadas en los últimos años.

El argumento central que se intenta desarrollar es que estos programas se han mantenido pero sólo en términos genérico-formales, ya que su implementación ha tomado distancia de un enfoque de derechos al quedar inmersos en un contexto de ajuste y recesión. En concreto, las alusiones presidenciales en favor de preservar las políticas sociales diseñadas en la ola progresista y las promesas por erradicar la pobreza, entrarían en contradicción con la inclinación de los gobiernos hacia una política económica ortodoxa, la concepción de un Estado de intervención mínima, y el creciente deterioro de las condiciones de vida de los sectores populares y medios.

Vale aclarar que los datos de la investigación provienen de la revisión de bibliografía específica, de discursos gubernamentales y de documentos y estadísticas; al tiempo que en la interpretación de los mismos se procura combinar aportes de diversos campos disciplinares: la teoría política, la historia social y el trabajo social. En cuanto a la organización, el artículo se estructura en tres apartados centrales. En primer lugar, se caracteriza el escenario político de Argentina y Brasil, puntualizando la transición desde el ciclo progresista hasta el ascenso de los gobiernos de Macri y Temer. En segunda instancia, se focaliza en la temática de las políticas sociales y su relación con los gobiernos. Nos concentramos en los principales programas destinados a revertir las situaciones de pobreza en Argentina y Brasil: la Asignación Universal por Hijo y el Bolsa Família. En tercer

lugar, se analizan las continuidades y los cambios en estos programas a partir de la asunción de los nuevos presidentes; tanto en lo que respecta a su funcionamiento y alcances, como en cuanto a los principios que subyacen a su implementación. 
En definitiva, en esta instancia de trabajo se considera el devenir de las políticas sociales (puntualizando en dos programas sociales concretos) como clave de análisis de las presidencias de Macri (Argentina) y Temer (Brasil). Ello busca generar aportes al debate en torno al nuevo contexto regional y las alternativas para dar respuesta a los desafíos que presentan nuestras sociedades.

\section{Aproximaciones desde el contexto político: del ciclo progresista al ascenso de las derechas}

Argentina y Brasil han transitado en lo que va del siglo XXI desde el «giro a la izquierda»² en el 20022003, hasta el reciente «giro a la derecha». En el caso argentino, la ola progresista se inauguró con la asunción de Néstor Kirchner (2003-2007) y se consolidó con las gestiones de Cristina Fernández (2007-2011, 2011-2015), ambos referentes del Frente para la Victoria (FPV). Mientras que en Brasil, comenzó con los gobiernos de Luiz Inácio da Silva (2003-2007, 2007-2011) y continuó con los de Dilma Rousseff (2011-2015, 2015-2016), ambos por el Partido dos Trabalhadores (PT).

Este ciclo progresista se caracterizó por la pretensión de recuperar el rol protagónico del Estado en la definición de la política económica, social e internacional. De allí que se estimuló la producción nacional y el mayor control y/o recuperación de sectores estratégicos de la economía; también la inversión en políticas públicas destinadas a reparar paulatinamente el tejido social, cuyas mejoras repercutirían, a su vez, en un incremento de la demanda del mercado interno. Al mismo tiempo, se buscó aunar esfuerzos para la integración regional y lograr mayores márgenes de soberanía frente a los organismos multilaterales de crédito.

Las medidas aplicadas por los gobiernos del llamado «giro a la izquierda» redundaron en indicadores macroeconómicos positivos, que daban cuenta de la reactivación económica y de las mejoras en la calidad de vida de los sectores medios y populares. En Argentina, al momento de asumir Néstor Kirchner como presidente (2003), el desempleo se encontraba en 20.4\%; mientras que para el 2011 se ubicaba en $6.7 \%$ (Encuesta Permanente de Hogares en Alonso y Di Costa, 2015). Diversos analistas no gubernamentales reconocieron que la gestión kirchnerista redujo la pobreza, que alcanzaba al 54\% de las personas en 2003, a alrededor del 20\% en 2011 (suplemento iEco 25/4/2012, citado en Alonso y Di Costa, 2015, p.38). Asimismo, también se observó una significativa reducción de la desigualdad, indicada por la variación del coeficiente de Gini, que pasó de 0.53 en 2002 a 0.44 a principios de 2010 (Rofman y Oliveri, 2011a en Alonso y Di Costa, 2015, p. 38).

En el caso de Brasil, en 2003 el desempleo medido por el Fondo Monetario Internacional alcanzaba al 13.7\% de la población; en 2011 ese porcentaje se había reducido al 7.8\% (FMI, 2019). Según el Banco Mundial en la década 2004-2014 alrededor de 28,6 millones de pobladores del país salieron de la pobreza, mientras que entre 2001 y 2013 cayó del 10\% al 4\% la extrema pobreza (entendida como la cantidad de brasileños que vive con menos de U\$S2,5 al día) (Clarín, 23/10/2017; El Pais, 23/04/2015). El coeficiente de Gini también mostró la reducción de la desigualdad, al pasar de 0.51 en 2006 a 0.47 en 2013 (OECD, 2019).

Vale advertir que el contexto económico internacional había resultado favorable para esta oleada progresista, debido a una tendencia que se dio a nivel mundial, a partir del 2003, de aumento de los precios y volúmenes de las exportaciones de origen agrícola, industrias extractivas y metales (Svampa, 2012). Estas producciones funcionaron como pilares del modelo de acumulación en los países analizados y sostuvieron el aumento del ahorro nacional para la redistribución. No obstante, la crisis económico-financiera del 2008, con epicentro en Estados Unidos, y la baja de los precios de los commodities en el mercado internacional desde 2013, generaron una desaceleración económica.

Conjuntamente cobraron fuerza las demandas de diversos sectores sociales que cuestionaban el devenir del modelo; en consonancia con ello, resonaron las voces de quienes criticaban los insuficientes cambios en materia económica, las consecuencias negativas de las prácticas extractivas para el medio ambiente y las generaciones futuras, como también la centralización del poder en torno a las figuras presidenciales. 
En este escenario comenzó a inscribirse el retraimiento o pérdida de iniciativa de los gobiernos progresistas y el ascenso de las opciones de «derecha» (Acosta et al, 2016; López Segrera, 2016a; Ansaldi, 2017). En Argentina, el partido PRO liderado por Mauricio Macri fue expandiendo su influencia durante casi una década desde la ciudad de Buenos Aires al resto del país, logrando la mayoría de los votos en la segunda vuelta presidencial de noviembre de 2015, para la cual conformó la coalición política «Cambiemos». En Brasil, fue una operación parlamentaria, jurídica y mediática la que logró la destitución de Dilma Rousseff en el año 2016 (Braz, 2017), y su reemplazo por el entonces vicepresidente Michel Temer del Movimiento Democrático Brasileño (ex aliado del PT en el gobierno y uno de los principales operadores del juicio político a Rousseff).

Es importante aclarar que, desde nuestra óptica, la noción de derecha podría revelarse como categoría vigente y pertinente para calificar a estos nuevos gobiernos, los cuales profundizarían los patrones de desigualdad en sus respectivos países a través de la transferencia de ingresos hacia los capitales concentrados. Esta característica ya había sido señalada por Norberto Bobbio al postular que la distinción central en la díada derecha-izquierda radicaba en el posicionamiento frente a la igualdad; así las derechas «están convencidas de que las desigualdades son un dato ineliminable» (Bobbio, 1997, p.15). Para el historiador argentino Waldo Ansaldi (2017) la opción por el mantenimiento de la desigualdad designa el núcleo duro del pensamiento, las prácticas y la concepción de derechas; en tanto que los nuevos rasgos de las actuales derechas son ocasionales y accesorios. De allí que el autor plantea, antes que la existencia de «nuevas derechas», la pregunta sobre «qué hay de nuevo en las derechas» (Ansaldi, 2017).

Entre las renovadas apariencias de las derechas en la actual coyuntura, vale destacar la consolidación de un formato de representación que privilegia la participación en cargos políticos de los propios dirigentes de las grandes corporaciones comerciales o financieras. En otras palabras, el comando del Estado recae sobre miembros directos de las elites empresariales que quieren hacer política (Acosta et al, 2016, p.2). En Argentina y Brasil esta tendencia se ha popularizado como «CEOcracia», en tanto los gabinetes se conforman con funcionariosempresarios, más vinculados a las actividades económicas privadas que a la función pública-política.

Otro rasgo que ha sido señalado como distintivo de las «nuevas» expresiones de derecha radicaría en el protagonismo otorgado a las herramientas del marketing político y, con ello, el privilegio de las formas, las imágenes y las estéticas; antes que los contenidos, los debates y los discursos ideologizados. Esto es especialmente evidente en el caso argentino, donde lo novedoso no sería el marketing en sí mismo sino su aplicación a la gestión cotidiana del Estado (Vommaro et al, 2015). Por su parte, Temer ha sido objeto de acusaciones por los gastos en esta materia, y durante el 2017 ha recibido asesoramiento para tomar una actitud más agresiva y redoblar promesas, procurando dejar de lado la mixtura entre «mayordomo y viejo profesor de latín» (Faria, 2017).

En referencia a la dimensión que pretendemos resaltar en este artículo, Emir Sader (2015) entiende que los gobiernos de las «nuevas» derechas se distinguen por pretender compatibilizar medidas económicas neoliberales con el mantenimiento de políticas sociales. Bajo esa óptica, tanto Mauricio Macri como Michel Temer han encontrado numerosos obstáculos para romper abiertamente con las políticas de inclusión implementadas y/o reforzadas en la década pasada; por ello, muchos de los referentes de sus espacios políticos debieron anunciar que cambiarían solo aquello que no se hacía bien, pero preservando y profundizando los logros sociales. Puede considerarse, como plantea Pablo Vommaro (2015) al analizar la situación argentina, que a pesar de retomar las doctrinas neoliberales, quienes asumieron el gobierno han revisado críticamente el neoliberalismo realmente existente durante la década del noventa, a partir de lo cual «no sólo se propone una política más transparente y eficiente sino también un Estado capaz de no socavar su autoridad por renunciar a una activa política social hacia los sectores populares» (Vommaro, 2015, p. 200).

En definitiva, más allá del álgido debate en torno al ascenso de las derechas en los gobiernos de Argentina y Brasil, vale profundizar en torno a esta supuesta vinculación entre políticas sociales y medidas de ajuste y liberalización económica. Ello requiere avanzar sobre un entendimiento de las políticas sociales, no como medidas aisladas o fragmentarias, sino como partes de la disputa por la hegemonía ${ }^{3}$ en un contexto político y socio-económico específico. 


\section{Aproximaciones desde las políticas y programas sociales}

La mirada sobre las políticas sociales permite aproximarnos a los modos en que el Estado interviene en lo social; ya que a través de ellas se fijan principios y postulados sobre la propia responsabilidad estatal, la definición de los sujetos merecedores de sus intervenciones y las condiciones de dicho merecimiento (Grassi, 2003). En ese sentido, resultan parte constitutiva «del trabajo político-cultural de producción de la hegemonía» de un proyecto político (Grassi, 2003, p. 13).

Las acciones, planes y programas que buscan erradicar la pobreza y la desigualdad resultan indicadores de en qué medida las sociedades logran extender y profundizar «la democracia y las pautas de inclusión» (Britos, 2006, p. 85). De allí que los programas sociales nunca podrían resultar suficientes si son acompañados por transformaciones regresivas para los sectores populares. Cabe advertir al respecto que la profundización de las medidas de corte neoliberal en los años 90 en la región latinoamericana, y principalmente a partir del proceso de reforma del Estado, afectaron sobremanera las políticas públicas de seguridad social que tenían como base el empleo formal. En este contexto emergieron situaciones de inestabilidad e inseguridad como consecuencia del aumento del desempleo y de trabajos precarios e informales (Neffa et. al, 2010). Para hacer frente a un panorama que multiplicaba los excluidos del modelo, se pusieron en funcionamiento los llamados Programas de Transferencias Condicionadas de Ingresos (PTCI). Estos programas pretendían extender la protección social a la población en situación de vulnerabilidad y exclusión socioeconómica; a la cual en la mayoría de los casos se le exigía el cumplimiento de ciertos requisitos en materia de educación y salud para ser beneficiario del programa. Tanto en Argentina como en Brasil se trató centralmente de programas con cupo y destinados a la pobreza extrema (Grassi, 2003).

Tal como se refirió en el apartado anterior, las estadísticas referidas a la primera década del siglo XXI evidenciaron que millones de personas lograron mejorar sus condiciones de vida, especialmente en lo que concierne a la pobreza e indigencia. Para ello, los gobiernos del ciclo progresista se valieron de diversas políticas sociales de amplio alcance que suponían un paso más allá en el tratamiento de la cuestión social. La Asignación Universal por Hijo (AUH) en Argentina y el Bolsa Família (BF) en Brasil, destacaron por ser PTCI que contaban con niveles de cobertura mucho más extensos que sus predecesores, con amplia prolongación en el tiempo, y rápida y efectiva implementación (Agis et al., 2009; Arcidiácono, 2016; Mourão e Macedo, 2012). Podría señalarse como la diferencia más importante el hecho de que se caracterizaron por inscribirse como parte de la seguridad social y no de la asistencia social, privilegiando un «enfoque de derechos» (Abramovich, 2006) que los colocara en sintonía con principios como la igualdad, la no discriminación, la universalidad. Desde esta perspectiva, los Estados nacionales se comprometían en la búsqueda por materializar el alcance a derechos universales como la salud, la educación, la alimentación, entre otros, conforme a las obligaciones adquiridas por la firma de distintos instrumentos internacionales en materia de Derechos Humanos (Pautassi, 2010; Cena, 2014).

No obstante, la AUH y el BF también fueron objeto de críticas en tanto mostraron limitaciones para garantizar la participación de los ciudadanos en su definición-implementación y para erradicar la estigmatización de los destinatarios como meros receptores de la asistencia del Estado (Cena, 2014). Al tiempo que también se ha observado que la mayor parte de la responsabilidad en cuanto a la contraprestación recae sobre las madres, reproduciendo las relaciones asimétricas entre varones y mujeres (Pautassi, 2009).

Particularmente, la Asignación Universal por Hijo surgió en el año 20094 y su implementación se prolongó hasta la actualidad. Consiste en una asignación mensual por cada hijo/a menor de 18 años (hasta un máximo de cinco). Es recibida por uno de los padres y se puede solicitar desde el momento del nacimiento. El beneficio se calificó como de alcance «universal» ${ }^{5}$ porque se destinó a todos los trabajadores desocupados o que realizaran sus actividades en la economía informal, con el objetivo de mejorar la calidad de vida y el acceso a la salud y la educación de los niños/as y adolescentes.

La ejecución e implementación de la AUH depende directamente de la Administración Nacional de la Seguridad Social (ANSES), este sistema intentó apuntalar el carácter universal del programa a partir de interrumpir las mediaciones a la hora de su distribución. El financiamiento se realiza con recursos del sistema de seguridad social, que incluye los aportes de los asalariados formales y los rendimientos anuales del Fondo de Garantía 
y Sustentabilidad del Régimen Previsional Público y de Reparto (Lo Vuolo, 2011), a lo que se suman créditos de organismos internacionales, especialmente del BM.

El monto de la asignación es de \$1578 (62 dólares), y en el caso de hijos con discapacidad (sin límite de edad) se cobran $\$ 5147$ (202 dólares) ${ }^{6}$. Cada mes el destinatario recibe el $80 \%$ del total del beneficio, y una vez por año se le solicita presentar la Libreta de Salud y Educación, que acredita la asistencia a un establecimiento educativo y controles de salud y vacunación. Cumplir con este trámite permite al titular cobrar el $20 \%$ que fue acumulado a nivel mensual durante el año vigente y, a la vez, renovar la asignación para el año siguiente. De este modo, las condicionalidades tendrían menor peso que en el caso de otras transferencias estatales, lo que puede interpretarse según Arcidiácono (2016) a partir del objetivo principal antes mencionado que es el acceso universal de niños/as y adolescentes a los servicios básicos, más allá de la contraprestación.

En el caso de Brasil, la Bolsa Família se originó en 2003 a partir de la decisión del gobierno federal de unificar otros programas de transferencias de renta (la Bolsa Escola, la Bolsa Alimentação, el Cartão Alimentaçao y el Auxílio-Gás) y se transformó en el programa de este tipo con mayor cobertura en el país e incluso en la región. Al igual que la $\mathrm{AUH}$, consiste en un programa de transferencia de recursos desde el Estado a las familias en situación de pobreza y extrema pobreza, con el objetivo de apoyarlas y de ampliar el acceso a servicios de educación y salud. Uno de sus rasgos distintivos es que no se presenta como «universal» sino de carácter masivo, ya que pueden acceder a ella las familias cuya renta por persona sea inferior a los 85 reales (25 dólares) por mes, y aquellas cuya renta se sitúe entre 85 y 170 reales mensuales (50 dólares) si tienen hijos de 0 a 17 años 7 .

El organismo encargado de la implementación del programa es el Ministério do Desenvolvimento Social ${ }^{8}$ (MDS) y operativamente realiza los pagos la Caixa Econômica Federal. Vale destacar que otra característica diferente a la de la AUH radica en que su gestión está descentralizada y los gobiernos de los estados y los municipios brasileños participan en su ejecución. En cuanto a las fuentes de financiamiento del programa, son principalmente nacionales (Tesoro Nacional), aunque también se utilizan los que brinda el Banco Interamericano de Desarrollo (BID) y el BM.

El paso previo para ser beneficiario del programa es el registro en el Cadastro Único para Programas Sociais do Governo Federal (CadÚnico), a partir del cual se realiza la selección y la evaluación de la situación particular de cada familia; de ello dependerá el monto que se reciba en concepto de BF. A diferencia de la cifra única que cobran los destinatarios de la AUH, en el caso del programa brasileño al beneficio básico de 85 reales se pueden sumar hasta cinco beneficios variables: por hijos de 0 a 15 años, por embarazo, por nutrición para bebés, por adolescentes de 16 o 17 años, entre otros. De esta manera, la cuantía de la transferencia depende de las singularidades de cada familia. Además, los beneficiarios de BF en situación de extrema pobreza cuentan desde 2012 con un monto que se calcula individualmente para cada familia y que cubre la diferencia entre el ingreso per cápita familiar y el valor de la línea de extrema pobreza.

En sintonía con la AUH, se establece como condición para recibir el beneficio la certificación de escolarización y cumplir con el plan de vacunación (o ir a controles de salud en el caso de los embarazos). Si las familias no presentan la información requerida o mejoran la situación de su renta, pueden ser eliminadas del programa, aunque en general no son obligadas a salir de inmediato por no cumplir con las condicionalidades expuestas. En ello incide que la gestión local de los programas se orienta a apoyar a las familias que no cumplen para evitar que sean sancionadas (Feijoó y Davolos, 2015).

En coyunturas previas a asumir la presidencia, tanto Macri como Temer se mostraron significativamente preocupados por las problemáticas sociales y se expresaron a favor de mantener las políticas sociales ya existentes. Mauricio Macri afirmaba en sus spots televisivos: «No voy a sacarle la ayuda a nadie. No voy a cambiar las cosas que sí se hicieron bien», «todos los chicos van a recibir apoyo del Estado». También sostenía que buscaría que la AUH llegara «sin trabas y con transparencia» (Macri, 2015). Una vez asumido el gobierno, en su discurso continuó presente esta postura, considerando a la AUH como «un programa exitoso» y que debía ampliarse para los niños que no hubieran accedido al plan, quienes «necesitan que el Estado esté cerca, y no solamente para repartir dinero, (...) [sino para] ayudar a la familia entera a incluirse» (Macri, 18/03/2016). 
En el discurso de apertura legislativa de 2017 se repitieron estas ideas sobre el rol del Estado, afirmando que «la mejor manera de igualar oportunidades es llevar el Estado donde antes no llegaba, sin clientelismos ni punteros» (Macri, 01/03/2017). En cuanto a la relación de la pobreza con los programas sociales, planteó que estos últimos (a los que reiteradamente denomina «planes sociales») «son necesarios en la urgencia, para acompañar y cuidar a los más vulnerables», pero que no pueden resolver por sí mismos la pobreza (Macri, 01/04/2018).

En el caso de Michel Temer, al asumir la presidencia definió como competencias del Estado cuidar la seguridad, la salud y la educación como espacios fundamentales de la órbita pública, mientras que el resto debe compartirse con la iniciativa privada. En su primer discurso como presidente en ejercicio afirmó la continuidad de los programas sociales, como Bolsa Família, Pronatec, Fundo de Financiamento Estudantil, Prouni y Minha Casa Minha Vida; al tiempo que rechazó la idea de que los nuevos gobiernos debían eliminar lo que hicieron los anteriores, y planteó la necesidad de realizar cambios atendiendo a lograr la «eficiencia administrativa», aunque «sin que ninguna de estas reformas altere los derechos adquiridos por los ciudadanos brasileños» (Temer, 12/ 05/2016).

Asimismo, el ex presidente brasileño ha afirmado que las medidas de austeridad fiscal pueden tener consecuencias sobre los derechos humanos, pero que es el costo de las economías desorganizadas el que recae desproporcionalmente sobre los más pobres. Evaluó la situación de Brasil como resultado de «la irresponsabilidad en el manejo de las cuentas públicas y del populismo» que adjudica a los gobiernos anteriores, manifestando que eso puso en riesgo la supervivencia de los programas sociales y la viabilidad de los sistemas de educación y salud, y en general los «derechos humanos que son conquistas de los brasileños, alcanzadas por el esfuerzo de generaciones» (Temer, 10/03/2017).

En 2017, Temer destacó el aumento del Bolsa Familía y aseguró la continuidad de obras de Minha Casa Minha Vida que estaban paralizadas, como así también el lanzamiento del programa Progredir y la «racionalización de la gestión de la salud». Tras un año ocupando la presidencia, la evaluación realizada sobre la vigencia de los programas sociales avalaba las medidas macroeconómicas tomadas durante la gestión: «Nuestro gobierno no es populista, mas tiene la sabiduría para mejorar los programas sociales sin comprometer la responsabilidad fiscal» (Temer, 12/05/2017).

\section{Los cambios en el contexto y su impacto en los programas sociales}

A los fines de reconstruir el contexto socio-económico de los dos mayores países de América del Sur, resultan elocuentes algunas cifras e indicadores provenientes de diversas fuentes estadísticas. ${ }^{9}$ Según el Observatorio de la Deuda Social de la Universidad Católica (OSDA-UCA, 2017a, 2017b), los niveles de pobreza en Argentina vienen experimentando una suba paulatina desde el 2012 en adelante; notoriamente en el tercer trimestre de 2016 se llegó al 32,9\%, tras un año en el que se generaron 1,5 millones de nuevos pobres que llevaron a la cifra de 13 millones de personas por debajo de la línea de la pobreza. En el mismo sentido, entre 2015 y 2016 se sumaron 600 mil personas en situación de indigencia, acumulando 2,7 millones de personas en total.

Con respecto a los datos oficiales, brindados por el Instituto de Estadísticas y Censos (INDEC), en el segundo semestre de 2017 la pobreza en los aglomerados urbanos fue del 17,9\% de los hogares, lo que equivale al 25,7\% de las personas (7.079.764); y la indigencia del 3,5\% de los hogares y el 4,8\% de las personas (1.323.747) (INDEC, 2018a). Al mismo tiempo, según las cifras de tal organismo, el costo de la canasta básica alimentaria (CBA, que demarca la línea de indigencia) en mayo de 2018 fue de \$2418,65 (100 dólares), mientras que comprar la canasta básica total (CBT, que señala la línea de pobreza) requirió \$6095 (252 dólares) (INDEC, $2018 b)^{10}$.

En el terreno de la distribución del ingreso, el coeficiente de Gini en 2016, según la Comisión Económica para América Latina y el Caribe (CEPAL), fue de 0,39. Según el INDEC (2018c), en el segundo trimestre de 2016 fue de 0,42; en el tercero subió a 0,45 y en el último trimestre de 2017 habría disminuido a 0,41, para volver a registrar una suba a 0,44 en el primer trimestre de 2018. Al mismo tiempo, el organismo revela que el 10\% de mayores ingresos percibe el 31,4\% del total del ingreso, contra el 1,2\% de los perceptores de menores ingresos (INDEC, 2018c). 
En el caso de Brasil, según la base de datos de la CEPAL (2018b), las tasas de pobreza e indigencia decrecieron anualmente desde 2003, cuando el 35,8\% era pobre y el 11,5\% indigente. Además, de acuerdo con registros de la Organización de las Naciones Unidas (ONU), entre 2000 y 2010 se redujo un 16\% la cantidad de residentes en favelas, lo cual significó una mejora en las condiciones de vida de más de 10 millones de brasileños (El Mundo, 2010). No obstante, según el Banco Mundial (BM), en el año 2016 entre 2,5 y 3,6 millones de personas cayeron por debajo del umbral de pobreza (140 reales al mes, aproximadamente 44 dólares) (Clarín, 23/10/2017).

En cuanto a los costos de vida en el país de habla portuguesa, la canasta básica varía según la zona geográfica en la cual se la calcule. En marzo de 2018 la de Río de Janeiro fue la más cara con 441,19 reales (131 dólares), seguida por la de São Paulo con 437,84 reales (130 dólares) y la de Porto Alegre, con un costo de 434,70 reales (129 dólares); mientras que la más barata se registró en Salvador, con 322,88 reales (96 dólares) (DIESSE, 2018a).

Según los datos publicados por el Instituto Brasileiro de Geografia e Estatística (IBGE) tras un estudio realizado en 2016, la mitad de los trabajadores brasileños cobran un salario inferior al mínimo (G1, 2017). Del total de trabajadores, 4,4 millones (el 5\%) recibieron ese año en promedio 73 reales por mes; mientras que 889 mil (1\% del total) recibieron 27 mil reales. En dicho período, el 43,4\% del total de los beneficios recibidos por los brasileños se concentró en las manos del 10\% de la población del país. Esto evidencia la desigualdad existente, dato que es avalado por las cifras del coeficiente de Gini que en 2015 fue de 0,51 (CEPAL, 2018a).

En definitiva, los indicadores anteriores resultan ilustrativos del agravamiento de los problemas de pobreza, indigencia y desigualdad. Estas cifras no resultarían ajenas a los cambios que experimentaron los programas sociales objeto de análisis. Tal como relatábamos en el apartado anterior, los nuevos gobiernos de Argentina y Brasil manifestaron sus intenciones de preservar las políticas sociales que implementaron quienes los precedieron, aunque en las prácticas llevadas adelante cuando efectivamente asumieron el gobierno prevalecerían las tensiones y rupturas, antes que las continuidades. Coincidimos con Ana Natalucci (2018) en que las gestiones analizadas operarían una redefinición de los principales programas sociales hacia la asistencia, reforzando una lógica individualista. De este modo, dejan de concebirse como integradores de las personas a la vida social, para pensarse como garantes de la subsistencia y la quietud de los sectores más desfavorecidos de la población.

En Argentina, desde el comienzo del gobierno de Cambiemos, la AUH ha persistido como una política masiva, los números de beneficiarios se mantuvieron e incluso ampliaron si se comparan con los períodos anteriores. En diciembre de 2017 alcanzó a 3.956.042 menores de 18 años, según las estadísticas oficiales de la ANSES; el gobierno presentó estos datos como «un crecimiento del 7\% en la cobertura» (Jefatura de Gabinete, noviembre de 2017). Este incremento quizás se explique en que, a partir del 2016, la AUH se extendió a los monotributistas sociales y se hizo compatible con el Seguro de Capacitación y Empleo y con otros Programas Nacionales de Empleo.

En el contexto brasileño, hacia el final del segundo gobierno de Dilma Rousseff la BF alcanzaba a alrededor de 13 millones de familias, es decir aproximadamente 50 millones de personas. En 2017, tras un año de gobierno de Michel Temer, desde la oposición se advirtió que el número de familias se redujo a 12,7 millones, lo que implicó desafectar a alrededor de 4 millones de brasileños. Frente a ello, desde el gobierno se plantea que el programa ha crecido, alcanzando a 14,1 millones de familias en marzo de 2018 (Informe do Governo, 16/03/2018).

No obstante, pese a que los gobiernos de Macri y de Temer continuaron con la implementación de la AUH y la BF, lo harían tan solo en términos genéricos-formales. Es decir, los programas se preservan, pero simultáneamente se aplican políticas económicas restrictivas que fomentan la concentración de los ingresos en aquellos sectores de mayores recursos; al tiempo que se genera una constante pérdida de poder adquisitivo que afecta a las clases populares. En este marco, tanto la AUH como la BF se consolidan en un rol que las define como contenedoras de la conflictividad social causada por las consecuencias del modelo de ajuste.

En esa sintonía, si bien la AUH continúa vigente no se le inyectaron recursos de importancia para potenciarla (Torres, 2018). En diciembre de 2017 se modificó la fórmula para el cálculo de las actualizaciones del 
monto de jubilaciones, pensiones y asignaciones familiares que se hacían conforme a la ley de movilidad sancionada en 2015. El nuevo método estipula cuatro aumentos teniendo en cuenta en un 70\% el Índice de Precios al Consumidor (IPC) del INDEC y en un 30\% la variación de la Remuneración Imponible Promedio de los Trabajadores Estables (RIPTE), logrando aumentos inferiores a los que se harían con el cálculo anterior ${ }^{11}$, y permitiendo al Estado un ahorro de más de 100 mil millones de pesos en prestaciones para el 2018 (Carrillo y Cufré, 2017). Al mismo tiempo, es pertinente señalar que un abanico de programas están siendo paulatinamente desactivados, como el Conectar Igualdad ${ }^{12}$ (consistente en la entrega de netbooks a alumnos secundarios), el Progresar (entrega de becas a jóvenes de 18 a 24 años que estudian) o el Procrear (créditos para la vivienda).

Para Juan Pablo Hudson (2017) la falta de estructura propia del macrismo ${ }^{13}$ explica que el gobierno se haya valido de los programas sociales previamente existentes para llegar a los sectores sociales más vulnerables. En definitiva, abrió a pleno los grifos del presupuesto destinado a la población considerada como sobrante por el mercado de trabajo, para «emparchar» su situación e intentar contener las iniciativas de protesta; en esa línea se inscribiría, por ejemplo, el apoyo del gobierno al Programa Argentina Trabaja y la aprobación de la Ley de Emergencia Social ${ }^{14}$ en diciembre de 2016:

«Es importante el presupuesto que destina la gestión de Macri para la pirámide y la base social, no significa que esos sectores estén viviendo momentos de fiesta o alegría, pero sí que el gobierno no ahorra recursos fiscales para poder contenerlos y alejar el conflicto social» (Hudson, 2017, s/d).

En Brasil, de acuerdo con INESC et al. (2018) un volumen significativo de recursos ha sido desviado desde los programas sociales para pagar servicios de la deuda. El mismo instituto calcula que en 2017 el gobierno de Temer redujo en un 55\% el financiamiento de los programas de seguridad alimenticia, entre ellos se destacan los recortes en el Programa de Aquisição de Alimentos (PAA) ${ }^{15}$. En cuanto al BF en particular, aunque aún no se haya concretado, el gobierno habría propuesto concentrarla en el $5 \%$ de los más pobres, lo cual implicaría que el beneficio se reduzca a 3 millones de familias (DHESCA, 2017). El partido gobernante también llegó a hacer público que de no aprobarse el proyecto de reforma del sistema previsional, habría que dar de baja el Bolsa Família (Peres, 2017).

También resulta válido destacar que, en materia de políticas sociales, los gobiernos en cuestión presentan escasas o nulas innovaciones, en el sentido de que prácticamente no se registran nuevos programas que den respuesta a las necesidades derivadas del empeoramiento de la situación económica por el aumento del costo de vida y de la desocupación. En algunas ocasiones se han unificado iniciativas diversas o se ha cambiado su denominación; es el caso de «Argentina Trabaja», «Ellas Hacen» y «Desde el Barrio», que fueron fusionadas bajo el nombre «Hacemos Futuro» tras dos años de gobierno de Cambiemos. Ello implicó un cambio en el modo de pensar estas políticas, desde una «concepción colectiva» hacia una lógica individualista (Arcidiácono y Bermúdez, 2018).

Al mismo tiempo, las escasas innovaciones parecen estar enfocadas en fortalecer el modelo del capitalismo financiero. Un ejemplo de esto es la multiplicación del acceso al crédito. En el caso argentino, con «Argenta» jubilados, pensionados y destinatarios de la AUH fueron habilitados para pedir préstamos personales ${ }^{16}$. En los primeros seis meses de funcionamiento, la ANSES efectivizó cerca de un millón y medio de créditos para beneficiarios de la AUH (Bercovich, 2017). En el caso de Brasil, para los beneficiarios del Bolsa Família existen los créditos del plan Progredir, lanzado por el gobierno de Michel Temer. La modalidad de estos préstamos implica, según Lo Vuolo, una tendencia global del capitalismo que consiste en:

«Una avanzada muy fuerte de las finanzas sobre las políticas sociales. Están creando un negocio financiero y un esquema redistributivo dentro de la clase trabajadora, porque los fondos acumulados por aportes y contribuciones de los empleados formales se invierten para extraer rentabilidad financiera de grupos laborales más precarizados. (...) Con el eufemismo de la 'inclusión financiera', convierten a los beneficios sociales en garantías colaterales de los préstamos» (Lo Vuolo, en Bercovich, 2017, s/p).

En concreto, en ninguno de los países analizados los montos percibidos en concepto de las asignaciones presentan aumentos reales significativos y su poder adquisitivo se va deteriorando progresivamente. Tampoco 
destacan iniciativas que potencien sus alcances ni nuevos programas de envergadura que intenten paliar las consecuencias de las medidas de política económica. En ese sentido, la inflación creciente, la fuerte devaluación de las monedas nacionales, el aumento generalizado de las tarifas, y el retraimiento de las prestaciones públicas/ estatales vuelven exiguos los -incluso escasos- esfuerzos en materia social.

En Argentina, en los primeros cuatro meses de 2016 los precios subieron aproximadamente 19\% (López Segrera, 2016b). A esto se suma el incremento de las tarifas de los servicios públicos como el gas y la energía eléctrica ${ }^{17}$, aumentos de precios superiores a los que se enuncian a través del Índice de Precios al Consumidor, que es la referencia a partir de la cual se negocian las paritarias (OPP UNDAV, 2018). El Estado Nacional ha recortado el presupuesto que se destinaba a financiar parcialmente el gasto de los hogares en los servicios públicos a través de un sistema de subsidios, y mientras que en el año 2015 el peso promedio de las tarifas rondaba el 6\% del ingreso mínimo laboral local, alcanzaría el 21\% en 2018 (OPP UNDAV, 2018). En Brasil, a poco tiempo de asumido el gobierno de Temer se aprobó en el poder legislativo su propuesta de Enmienda Constitucional (PEC 241 o 55) que establece un congelamiento del gasto público para los próximos 20 años. En las áreas de salud y educación comenzará a aplicarse después de 2018, y se ha señalado que como los gastos de esos ámbitos crecen anualmente en un ritmo superior al de la inflación, la medida implicará un recorte en las prestaciones y afectará la calidad de dichos servicios públicos (Alessi, 2016).

En ambos países las iniciativas de reforma previsional y laboral parecen conllevar fuertes impactos para los sectores trabajadores, tanto de la economía formal como informal, constituyendo estos últimos la principal población beneficiaria de las asignaciones aquí analizadas. Mientras que Argentina aprobó ya su reforma previsional y aún queda pendiente la laboral, en el caso de Brasil sucedió a la inversa. En ambos contextos se argumenta desde los gobiernos que estos proyectos son necesarios para reducir el déficit y modernizar las disposiciones, acorde con las nuevas realidades socio-laborales.

Como consecuencia del contexto de políticas de ajuste comienzan a generarse conflictos y protestas sociales, y la respuesta de los gobiernos muchas veces apela a intentos de invisibilización o de criminalización. En Brasil, se perpetúa «una lógica basada en dispositivos de control estructurados por la violencia del Estado y fundados en la represión y el racismo» (DHESCA, 2017). En Argentina, desde la asunción del gobierno de Macri «las propuestas y discursos oficiales relacionados con la protesta social se han centrado en los límites de lo que pueden hacer los manifestantes, en detrimento del peso que anteriormente se había puesto en regular la actuación policial» (CELS, 2017). En este escenario las políticas sociales se mantienen, pero principalmente como estrategias para la contención de la conflictividad social, antes que como herramientas para favorecer la universalización de los derechos.

\section{Conclusiones}

Este artículo se vincula con una investigación más extensa, la cual aspira a identificar las continuidades, rupturas y tensiones en la transición del «giro a la izquierda» hacia el «giro a la derecha» en Argentina y Brasil durante los últimos años del siglo XXI. En esta oportunidad, se ha intentado poner en cuestión el supuesto afán de los gobiernos de Macri (Argentina) y de Temer (Brasil) por preservar políticas sociales de vocación universal creadas durante la década previa, acompañadas con un renovado impulso de medidas de corte neoliberal.

En concreto, el análisis se circunscribió al devenir de dos programas sociales que destacaron por su amplia magnitud y alcance: AUH (Argentina) y BF (Brasil). Dichos programas fueron creados durante las gestiones de Fernández (Argentina, 2009) y Da Silva (Brasil, 2003) y continúan implementándose. Nuestros argumentos sostienen que las alusiones en favor de preservar los programas sociales diseñados en la ola progresista y las promesas por redoblar apuestas para erradicar la pobreza y la movilidad social descendente, entrarían en contradicción con la inclinación de los gobiernos de Macri y Temer hacia una política económica ortodoxa, la concepción de un Estado de intervención mínima, y el creciente deterioro de las condiciones de vida de los sectores medios y populares. En definitiva, tanto la AUH como la BF se alejarían de la idea de contribuir a la conquista de derechos universales, y serían más bien consideradas estrategias para amortiguar las lesivas consecuencias de las medidas de ajuste y colocar un freno a la conflictividad social ascendente. 
Como posible contribución de nuestro trabajo, se ha afirmado además que las políticas sociales no constituyen únicamente un conjunto de programas técnicos, sino que implican definiciones del problema y del sujeto destinatario. A su vez, su análisis no podría realizarse en abstracción del contexto en que se insertan y del proyecto político en el que se enmarcan. Las políticas sociales resultan, entonces, aspectos constitutivos del entramado de cada gobierno y herramientas fundamentales para consolidar su aspiración hegemónica en el territorio.

Finalmente, en tanto las apreciaciones aquí explayadas atañen a procesos actualmente en curso, sería pertinente promover nuevas y continuas revisiones, sumando a futuro el análisis de los impactos que estas políticas sociales tienen en las voces de los sujetos titulares. Al mismo tiempo, resultaría interesante avanzar en un análisis más exhaustivo de la política social de ambos gobiernos (Macri y Temer, e incluso Bolsonaro), lo que implicaría considerar no sólo la implementación de la Asignación Universal y la Bolsa Família, sino sumar otros programas, y principalmente indagar qué hacen los actores sociales con ellos.

\section{Notas}

${ }^{1}$ La elección de Andrés Manuel López Obrador, representante de la centro-izquierda, en 2018, parece marcar una inflexión en este sentido.

${ }^{2} \mathrm{Al}$ respecto se pueden consultar otros trabajos de los/as autores/as de este artículo.

${ }^{3}$ Que un proyecto político tenga hegemonía sobre el resto quiere decir que ha logrado trascender su carácter particular para asumir, a la vez, la función de representación universal (Laclau y Mouffe, 2004). De allí que el proceso hegemónico no se comprende por la mera recurrencia a la fuerza ni exclusivamente por las victorias electorales; sino que atañe al despliegue de un arduo y constante trabajo político-cultural, que busca seducir a los más amplios sectores sociales.

${ }^{4}$ Por decreto 1602/09 se incorporó a la ley 24.714 de Asignaciones Familiares.

${ }^{5}$ Justamente Cena (2014) señala sus limitaciones al dejar fuera de cobertura, por ejemplo, a los nacidos en territorio argentino cuyo progenitor no sea nacional o posea una estancia menor a tres años de residencia en el país; o a aquellos niños, niñas y adolescentes que tengan a sus progenitores privados de la libertad.

${ }^{6}$ Los montos corresponden a los valores actualizados al 1 de junio de 2018 (la cifra en dólares se calculó según el precio vigente el último día hábil de mayo, \$25,40). En una zona delimitada (provincias de La Pampa, Chubut, Neuquén, Río Negro, Santa Cruz, Tierra del Fuego, Antártida e Islas del Atlántico Sur y Partido de Patagones en la provincia de Buenos Aires) la AUH asciende a \$2052 (80 dólares), y en el caso de hijos con discapacidad a \$6330 (263 dólares).

${ }^{7}$ Los valores considerados en este apartado son los vigentes en abril de 2018.

${ }^{8}$ Denominado Ministério do Desenvolvimento Social e Combate à Fome entre 2004 y 2016.

${ }^{9}$ En lo que concierne a Argentina, a partir del año 2017 se consideran los datos oficiales del Instituto de Estadísticas y Censos. Sin embargo para los años previos se ha recurrido a los registros realizados por una institución privada (la Universidad Católica Argentina) debido a la advertencia del INDEC que refiere que «las series estadísticas publicadas con posterioridad a enero 2007 y hasta diciembre 2015 deben ser consideradas con reservas, excepto las que ya hayan sido revisadas en 2016 y su difusión lo consigne expresamente» (INDEC, 2019) y que deriva de diversos cuestionamientos que se han realizado a la forma de medición que se utilizó en esos años y los resultados obtenidos a partir de ello. Por otra parte, a partir de 2015 se seleccionaron datos de ambas fuentes para dejar constancia de la existencia de diferencias entre los registros oficiales (los del INDEC) y extraoficiales (los de la UCA y la CEPAL).

${ }^{10}$ El cálculo en dólares se realizó en función a un dólar de \$24,15, promedio de la cotización del dólar para la venta en el Banco de la Nación Argentina en los días hábiles del mes de mayo.

${ }^{11}$ Para la Asignación Universal por Hijo la modificación de la fórmula permitiría en marzo un beneficio que pasaría de 1412 a 1492 pesos. Si se hubiera aplicado la movilidad del gobierno de Cristina Fernández, la AUH hubiera ascendido a 1581 pesos, 89 pesos por arriba del monto ahora acordado (Infobae, 2018)

${ }_{12}$ Programa dado de baja formalmente por decreto el 2 de mayo de 2018. El documento estipula la creación de «Aprendamos Conectados», nueva iniciativa que apuesta a desarrollar «en las escuelas núcleos de alfabetización digital», aunque no queda en claro cómo se implementará ni con qué fondos contará (Carrillo y Cufré, 2017).

${ }^{13}$ Recordemos que al llegar a la presidencia el partido de Mauricio Macri llevaba diez años desde su fundación formal en la Ciudad 
de Buenos Aires (primero como Compromiso para el Cambio, luego como Unión PRO y finalmente en 2010 como PRO), y la incorporación de la Unión Cívica Radical en la alianza Cambiemos para esas elecciones pretendía sumar la estructura a nivel nacional y las bases populares del partido centenario para fortalecer al partido capitalino.

${ }^{14}$ La Ley N ${ }^{\circ} 27345$ crea un Consejo de la Economía Popular y también el Salario Social Complementario (SSC) en la órbita del MDSN. Por el momento lo están cobrando cerca de 150.000 personas.

${ }^{15} \mathrm{El}$ presupuesto autorizado al MDS y la Secretaria de Desenvolvimento Agrário en ese año fue de un 31\% menor de lo autorizado en 2014, evidenciando un recorte del 69\% en tres años.

${ }^{16}$ Estos últimos consisten en tres mil pesos por hijo (a reintegrar en un año) o de cinco mil pesos por hijo (a reintegrar en dos años), que luego se pagan en cuotas que directamente se debitan de la asignación mensual (\$266 mensuales por dos años por cada cinco mil pesos de préstamo, esto implica un $24 \%$ de interés anual).

${ }^{17}$ Según el Observatorio de Políticas Públicas de la Universidad Nacional de Avellaneda (2018), Argentina es el país de la región que en los últimos tres años ha registrado el mayor incremento en el peso de los servicios públicos sobre los salarios.

\section{Bibliografía}

Abramovich, V. (2006). Una aproximación al enfoque de derechos en las estrategias y políticas de desarrollo. Revista de la CEPAL (88), 35-50.

Acosta, Y., Giordano, V. y Soler, L. (2016). América Latina: nuestra. Cuadernos del Pensamiento Crítico, (36), 1-4. Recuperado de http://biblioteca.clacso.edu.ar/clacso/se/20160805024237/Cuaderno-PCL-N36.pdf

Agis, E., Cañete, C., Panigo, D. (2009). El impacto de la asignación universal por hijo en Argentina. SID PROFOPE CEIL-PIETTE.

Alonso, G. y Di Costa, V. (2015). Más allá del principio contributivo: cambios y continuidades en la política social argentina, 2003-2011. Estudios Sociológicos, 33 (97), 31-62. Recuperado de: https:// estudiossociologicos.colmex.mx/index.php/es/article/view/16/16

Alessi, G. (13 de diciembre de 2016). Entenda o que é a PEC 241 (ou 55) e como ela pode afetar sua vida. El País Brasil. Recuperado de https://brasil.elpais.com/brasil/2016/10/10/politica/1476125574_221053.html

Ansaldi, W. (2017). Arregladitas como para ir de boda. Nuevo ropaje para las viejas derechas. Theomai, (35), 22-51. Recuperado de http://www.revista-theomai.unq.edu.ar/NUMERO_35/2.\%20Ansaldi.pdf

Arcidiácono, P. (2016). La asignación universal en su laberinto. Bordes, Revista de Política, Derecho y Sociedad, (1), 131-139. Recuperado de http://revistabordes.com.ar/wp-content/uploads/2016/09/19-La-asignacion.pdf

Arcidiácono, P. y Bermúdez, Á. (25 de mayo de 2018). Cambiemos disolvió la concepción colectiva del 'Ellas hacen’. Página/12. Recuperado de https://www.pagina12.com.ar/116979-cambiemos-disolvio-la-concepcioncolectiva-del-ellas-hacen

Bercovich, A. (2017). La victoria del chori financiero. Revista Crisis, (31). Recuperado de http:// www.revistacrisis.com.ar/notas/la-victoria-del-chori-financiero

Bobbio, N. (1997). Derecha e izquierda, razones y significados de una distinción política. Madrid, España: Gráfica Internacional.

Braz, M. (2017). O golpe nas ilusões democráticas e a ascensão do conservadorismo reacionário. Serv. Soc. Soc., (128), 85-103. Recuperado de http://www.scielo.br/scielo.php?pid=S010166282017000100085\&script=sci_arttext 
Britos, N. (2006). Ámbito profesional y mundo del trabajo: políticas sociales y trabajo social en los noventa. Buenos Aires, Argentina: Espacio.

Carrillo, C. y Cufré, D. (14 de noviembre de 2017). La fórmula de la infelicidad 2. Página 12. Recuperado de https:/ /www.pagina12.com.ar/78006-la-formula-de-la-infelicidad-2

Cena, R. (2014) Enfoque de derechos humanos en políticas sociales: Asignación universal por hijo para protección social y Derechos Económicos, Sociales y Culturales en debate. Red Universitaria sobre Derechos Humanos y Democratización para América Latina (6), 31-49.

Faria, T. (1 de enero de 2017). E Temer descobriu o marketing. Poder 360. Recuperado de https:// www.poder360.com.br/analise/e-temer-descobriu-o-marketing/

Feijoó, M. y Davolos, P. (2015) Es hora de debatir a fondo las políticas sociales en América Latina. Nueva Sociedad. Recuperado de http://nuso.org/documento/debatir-sobre-las-politicas-sociales-en-america-latina/

Grassi, E. (2003). Políticas y problemas sociales en la sociedad neoliberal. Buenos Aires, Argentina: Espacio.

Hudson, J. P. (2017). Continuidad en los parches. Revista Crisis, (31). Recuperado de http://www.revistacrisis.com.ar/ notas/continuidad-en-los-parches

Laclau, E. y Mouffe, C. (2004). Hegemonía y estrategia socialista. Buenos Aires: Fondo de Cultura Económica.

López Segrera, F. (2016a). América Latina: crisis del posneoliberalismo y ascenso de la nueva derecha. Buenos Aires, Argentina: CLACSO.

(2016b). Nueva derecha, neoliberalismo y posneoliberalismo. Rebelión. Recuperado de http:// www.rebelion.org/noticia.php?id=212452

Lo Vuolo, R. (2011). Los programas de transferencias monetarias condicionadas en América Latina y las perspectivas de la renta básica o ingreso ciudadano: un análisis en base a los programas «Bolsa família» de Brasil y «Asignación universal por hijo para protección social». Revista Internacional de Pensamiento Político, (6), 193-222. Recuperado de https://www.upo.es/revistas/index.php/ripp/article/view/1869

Mourão, L. y Macedo de Jesús, A. (2012). Programa Bolsa Família: uma análise do programa de transferência de renda brasileiro. Field Actions Science Reports (3) 1-7. Recuperado de http:// journals.openedition.org/ factsreports/1319

Natalucci, A. (2018). El neoliberalismo en acto: políticas sociales y experiencias organizativas en Argentina (20092016). En Polis, Revista Latinoamericana, (49), 103-125. doi: 10.4067/S0718-65682018000100103

Neffa, J. C. (ed.) (2011). Políticas públicas de empleo I (1989-1999). Empleo, desempleo \& políticas de empleo, (5). Buenos Aires: CEIL/Piette Conicet.

Pautassi, L. (2010). El aporte del enfoque de Derechos a las políticas sociales. Una breve revisión. Taller de expertos Protección social, pobreza y enfoque de derechos: vínculos y tensiones. Recuperado de: http://www.eclac.cl/ dds/noticias/paginas/7/37567/LauraPautassi_Derechos_polsoc.pdf

(2009). Programas de transferencias condicionadas de ingresos ¿Quién pensó en el cuidado? La experiencia en Argentina». En Seminario Regional Las familias latinoamericanas interrogadas. Hacia la articulación del diagnóstico, la legislación y las políticas. Santiago de Chile: CEPAL.

Peres, J. (2017). Brasil: la vuelta al siglo XIX. Nueva Sociedad. Recuperado de http://nuso.org/articulo/brasil-lavuelta-al-siglo-xix/ 
Sader, E. (24 de noviembre de 2015). ¿Hay una nueva derecha en América Latina?. Página 12. Recuperado de https:/ /www.pagina12.com.ar/diario/contratapa/13-286779-2015-11-24.html

Svampa, M. (2012). Consenso de los commodities, giro ecoterritorial y pensamiento crítico en América Latina. OSAL, (32), 15-38. Recuperado de http://biblioteca.clacso.edu.ar/clacso/osal/20120927103642/OSAL32.pdf

Torres, P. (2018). ¿Qué pasa con las políticas sociales durante el macrismo?. Recuperado de http:// www.agenciapacourondo.com.ar/opinion/que-pasa-con-las-politicas-sociales-durante-el-macrismo

Vommaro, G., Morresi, S. y Bellotti, A. (2015). Mundo PRO. Buenos Aires, Argentina: Planeta.

Vommaro, G. (2015). La nueva derecha argentina y las paradojas de este tiempo. Revista Horizontes del Sur, (2), 198-205. Recuperado de http://horizontesdelsur.com.ar/wp-content/uploads/2015/07/24.Vommaro.pdf

\section{Fuentes}

\section{- Discursos y declaraciones}

Macri, Mauricio. 2015. Spots:

«Asignación Universal» (en línea: https://www.youtube.com/watch?v=883aifK_Xc0)

«Lo que no voy a hacer» (en línea: https://www.youtube.com/watch?v=J4qNzQUsCAEM;

«Salud» (en línea: https://www.youtube.com/watch?v=dKANdG1xlOQ).

Macri, Mauricio. 1 de marzo de 2016. Discurso en la 134 apertura de las sesiones ordinarias del Congreso. En línea: https://www.casarosada.gob.ar/informacion/discursos/35651-palabras-del-presidente-mauricio-macri-en-la134-apertura-de-sesiones-ordinarias-del-congreso Macri, Mauricio. 18 de marzo de 2016. Discurso en Resistencia, Chaco. En línea: https://www.casarosada.gob.ar/informacion/discursos/40519-palabras-del-presidente-mauricio-macri-al-anunciar-un-prestamo-del-banco-mundial

Macri, Mauricio. 1 de marzo de 2017. Discurso de la 135ª apertura de las sesiones ordinarias del Congreso. En línea: https://www.casarosada.gob.ar/informacion/discursos/38791-discurso-del-presidente-mauricio-macri-en-laapertura-del-135-periodo-de-sesiones-ordinarias-del-congreso-de-la-nacion-argentina

Macri, Mauricio. 1 de abril de 2018. ««Está pasando: cada vez más argentinos están saliendo de la pobreza», dijo Macri». En La Gaceta de Tucumán. En línea: https://www.lagaceta.com.ar/nota/766022/actualidad/esta-pasando-cada-vez-mas-argentinos-estan-saliendo-pobreza-dijo-macri.html

Temer, Michel. Presidente em Exercício. 12 de mayo de 2016. En línea: http://micheltemer.com.br/opinioes/presidente-em-exercicio/

Temer, Michel. O Brasil e os direitos humanos. 10 de marzo de 2017. En línea: http://micheltemer.com.br/opinioes/ o-brasil-e-os-direitos-humanos/

Temer, Michel. O futuro é agora. 12 de mayo de 2017. En línea: http://micheltemer.com.br/opinioes/o-futuro-eagora/

\section{- Estadísticas}

Administración Nacional de la Seguridad Social. (2018). Asignación Universal por Hijo. Recuperado de https:// www.anses.gob.ar/prestaciones/asignacion-universal-por-hijo-auh

Centro de Estudios Legales y Sociales (CELS). (2017). El derecho a la protesta social en la Argentina. Ciudad Autónoma de Buenos Aires, Argentina: CELS.

Comisión Económica para América Latina y el Caribe (CEPAL). (2018a). Panorama Social de América Latina, 2017. Recuperado de https://repositorio.cepal.org/bitstream/handle/11362/42716/4/S1800002_es.pdf

Comisión Económica para América Latina y el Caribe (CEPAL). (2018b). Brasil: perfil nacional socio-demográfico. Base de datos y publicaciones estadísticas. Recuperado de http://estadisticas.cepal.org/cepalstat/ Perfil_Nacional_Social.html?pais=BRA\&idioma=spanish

Departamento Intersindical de Estatística e Estudos Socioeconômicos (DIEESE). (2017). Pesquisa Nacional da Cesta Básica de Alimentos: Banco de dados. Recuperado de https://www.dieese.org.br/cesta/produto 
Plataforma Brasileira de Direitos Humanos Econômicos, Sociais, Culturais e Ambientais (DHESCA). (2017). Relatório sobre o Impacto da Política Econômica de Austeridade nos Direitos Humanos. Recuperado de http:// austeridade.plataformadh.org.br/files/2017/11/publicacao_dhesca_baixa.pdf

Fondo Monetario Internacional. (FMI) (2019) IMF Data mapper: Unemployment rate. Recuoerado de: https:// www.imf.org/external/datamapper/LUR@WEO/ARG/BRA

Governo de Brasil. (2018). Bolsa Família realiza pagamentos de $R$ \$ 2,5 bilhões em março. Recuperado de http:// www.brasil.gov.br/editoria/cidadania-e-inclusao/2018/03/bolsa-familia-realiza-pagamentos-de-r-2-5-bilhoesem-marco

Instituto Nacional de Estadísticas y Censos. (2018a). Informes Técnicos. Condiciones de vida. Valorización mensual de la Canasta Básica Alimentaria y de la Canasta Básica Total. Gran Buenos Aires. Cifras estimadas a febrero de 2018. Recuperado de https://www.indec.gob.ar/uploads/informesdeprensa/canasta_03_18.pdf

Instituto Nacional de Estadísticas y Censos. (2018b). Informes Técnicos. Trabajo e ingresos. Evolución de la distribución del ingreso (EPH). Cuarto trimestre de 2017. Recuperado de https://www.indec.gob.ar/uploads/ informesdeprensa/ingresos_4trim17.pdf

Instituto Nacional de Estadísticas y Censos. (2018c). Informes Técnicos vol. $1 n^{\circ} 114$. Trabajo e ingresos vol. $1 n^{o}$ 5. Evolución de la distribución del ingreso (EPH). Primer trimestre de 2017. Recuperado de http:// www.indec.gob.ar/uploads/informesdeprensa/ingresos_1trim17.pdf

Instituto de Estudos Socioeconômicos (INESC), Oxfam Brasil y Centro para os Direitos Econômicos e Sociais (CESR). (2018). Brasil. Direitos humanos em tempos de austeridade. Recuperado de http://www.oxfam.org.br/ sites/default/files/arquivos/Fact_Sheet_2_Portugues_V_digital_2.pdf

Jefatura de Gabinete de Ministros. (2017). Carta de Jefatura de Gabinete: Tres pilares para el desarrollo humano. Recuperado de https://www.casarosada.gob.ar/images/201711/CJG_07.pdf

Ministério do Desenvolvimento Social. Bolsa Família: O que é. Recuperado de http://mds.gov.br/assuntos/bolsafamilia/o-que-e (Última consulta: 05/04/2018)

Observatorio de la Deuda Social Argentina de la Universidad Católica Argentina. (2017a). Estimaciones de Pobreza en la Argentina urbana 1980-2016. Documento de Divulgación. Recuperado de http://www.uca.edu.ar/uca/ common/grupo68/files/2017-Observatorio-Estimaciones-Pobreza-1980-2016.pdf

Observatorio de la Deuda Social Argentina de la Universidad Católica Argentina. (2017b). Pobreza y desigualdad por ingresos en la Argentina urbana 2010-2017. Recuperado de http://www.uca.edu.ar/uca/common/grupo68/files/2017-Observatorio-Informe-pobreza-por-Ingresos-Final.pdf

Observatorio de Políticas Públicas de la Universidad Nacional de Avellaneda. (2018). Infografía: Costo tarifario. Recuperado de http://undav.edu.ar/general/recursos/adjuntos/20367.pdf

Organisation for Economic Co-operation and Development. OECD. (2019). Income inequality (indicator). doi: 10.1787/459aa7f1-en

\section{- Prensa}

Las favelas en Brasil se redujeron un 16\% en la última década. (18 de marzo de 2010). El Mundo. Recuperado de http://www.elmundo.es/america/2010/03/18/brasil/1268946562.html

Brasil redujo la población de las favelas en 16\% durante la última década. (19 de marzo de 2010). América Economía. Recuperado de http://7.americaeconomia.com/politica-sociedad/politica/brasil-redujo-la-poblacion-de-lasfavelas-en-16-durante-la-ultima-decada

Brasil lidera la reducción de la pobreza, según el Banco Mundial. (25 de abril de 2015). El Pais. Recuperado de https://elpais.com/internacional/2015/04/23/actualidad/1429745195_504833.html

La Anses oficializó los aumentos en jubilaciones, pensiones y Asignación Universal por Hijo. (4 de junio de 2018). Infobae. Recuperado de https://www.infobae.com/economia/2018/06/04/la-anses-oficializo-los-aumentos-enjubilaciones-pensiones-y-asignacion-universal-por-hijo/

Más de 143.000 familias brasileñas volvieron este año al Bolsa Familia. (31 de julio de 2017). EFE. Recuperado de https://www.efe.com/efe/america/economia/mas-de-143-000-familias-brasilenas-volvieron-este-ano-al-bolsafamilia/20000011-3340484

Tras una década de auge, millones vuelven a la pobreza en Brasil. (23 de octubre de 2017). Clarín. Recuperado de https://www.clarin.com/mundo/decada-auge-millones-vuelven-pobreza-brasil_0_Skn3A_s6W.html 